\title{
PPM PEMBERDAYAAN MASYARAKAT DALAM PENGOLAHAN TANAMAN OBAT SEBAGAI OBAT TRADISIONAL DI DESA MENDALO INDAH JAMBI LUAR KOTA
}

\author{
Elisma1), Havizur Rahman'1), Uce Lestari1) \\ 1) Program Studi Farmasi, Fakultas Sains dan Teknologi, Universitas Jambi, Jambi, Indonesia \\ Corresponding author : Havizur Rahman \\ E-mail : havizurrahman27@unja.ac.id.
}

Diterima 8 Agustus 2020, Direvisi 25 Agustus 2020, Disetujui 10 September 2020

\begin{abstract}
ABSTRAK
Dalam dekade belakangan ini di tengah banyaknya jenis obat modern di pasaran dan munculnya berbagai jenis obat modern yang baru, terdapat kecenderungan global untuk kembali ke alam (back to nature). Faktor yang mendorong masyarakat untuk mendayagunakan obat bahan alam antara lain mahalnya harga obat modern/sintetis dan banyaknya efek samping. Selain itu faktor promosi melalui media masa juga ikut berperan dalam meningkatkan penggunaan obat bahan alam. Oleh karena itu obat bahan alam menjadi semakin populer dan penggunaannya meningkat tidak saja di negara sedang berkembang seperti Indonesia, tetapi juga pada negara maju. Jenis obat tradisional yang digunakan dapat berupa obat tradisional buatan sendiri, jamu gendong maupun obat tradisional industri pabrik. Penggunaan tumbuhan obat tidak sesederhana seperti yang dipikirkan orang selama ini. Semua harus dipelajari dan memerlukan pengalaman tersendiri. Pemakaian obat tradisional juga harus mempertimbangkan takaran/dosis dan cara pengolahan yang tepat agar tujuan terapi tercapai. Namun belum banyak masyarakat mengetahui cara pembuatan obat tradisional yang baik, dimulai dari bagian tanaman obat yang diambil sampai pada tahap pengolahannya. Salah mengenali tumbuhan obat yang dimaksud juga tidak akan menyembuhkan penyakit, apalagi salah menggabungkan beberapa tumbuhan obat yang khasiatnya berlawanan. Pengabdian yang dilaksanakan di Desa Mendalo Indah Kecamatan Jambi Luar Kota ini bertujuan untuk memberikan informasi mengenai cara pengolahan obat tradisional yang teapat. Metode yang dilaksanakan pada Program PKM yaitu penyuluhan dan pelatihan. Setelah pengabdian ini dilaksanakan dapat terlihat bahwa masyarakat telah mengetahui dan menerapkan cara pengolahan obat tradisional yang baik. Diharapkan dengan ini tujuan pengobatan dapat tercapai secara maksimal dan efek samping minimal sehingga berimbas pada peningkatan kualitas kesehatan masyarakat.
\end{abstract}

Kata kunci: obat tradisional; pengolahan; desa mendalo indah.

\begin{abstract}
In the last decade amidst the many types of modern medicines on the market and the emergence of various types of new modern medicines, there is a global tendency to return to nature. Factors that encourage people to utilize natural medicines include the high price of synthetic drugs and the many side effects. In addition, promotion factors through the mass media also play a role in increasing the use of natural medicines. Therefore natural medicines have become increasingly popular and their use is increasing not only in developing countries like Indonesia but also in developed countries. The type of traditional medicine used can be in the form of homemade traditional medicine, herbal medicine as well as traditional industrial medicine. The use of medicinal plants is not as simple as people have thought so far. All must be learned and requires its own experience. The use of traditional medicine must also consider the correct dosage and treatment method so that the therapeutic goals are achieved. But not many people know how to make traditional medicines that are good, starting from the part of medicinal plants taken to the processing stage. It is also wrong to recognize the medicinal plants which will not cure the disease, moreover one combines several medicinal plants which have opposite properties. The service that was carried out in Mendalo Indah Village, Jambi, Outer City District, was aimed at providing information on how to treat traditional medicines properly. The method implemented in the PKM Program is counseling and training. After this service is carried out, it can be seen that the community has known and implemented a good method of processing traditional medicines. It is expected that using this treatment goal can be achieved optimally and minimal side effects so that the impact on improving the quality of public health.
\end{abstract}

Keywords: traditional medicine; processing; mendalo indah village 


\section{PENDAHULUAN}

Obat tradisional adalah bahan atau ramuan bahan yang berasal dari tumbuhan, hewan, mineral, sediaan sarian (galenik) atau campuran dari bahan tersebut, yang secara turun temurun telah digunakan untuk pengobatan berdasarkan pengalaman. Obat tradisional Indonesia atau obat asli Indonesia yang lebih dikenal dengan nama jamu, umumnya campuran obat herbal, yaitu obat yang berasal dari tanaman. Bagian tanaman yang digunakan dapat berupa akar, batang, daun, umbi atau mungkin juga seluruh bagian tanaman. Indonesia yang beriklim tropis merupakan Negara dengan keanekaragaman hayati terbesar kedua di dunia setelah Brazil. Indonesia memiliki sekitar $25 \quad 000-30 \quad 000$ spesies tanaman yang merupakan $80 \%$ dari jenis tanaman di dunia dan $90 \%$ dari jenis tanaman di Asia.

Dalam dekade belakangan ini di tengah banyaknya jenis obat modern dipasaran dan munculnya berbagai jenis obat modern yang baru, terdapat kecenderungan global untuk kembali ke alam (back to nature). Faktor yang mendorong masyarakat untuk mendayagunakan obat bahan alam antara lain mahalnya harga obat sintetis dan banyaknya efek samping. Obat tradisional mungkin digunakan sebagai obat alternatif karena mahalnya atau tidak tersedianya obat modern/sintetis dan adanya kepercayaan bahwa obat tradisional lebih aman. Namun tidak semua obat tradisional aman. Kemanan obat tergantung dari dosis yang dikonsumsi. Masyarakat meyakini obat tradisional dapat mengobati penyakit ringan sampai berat. Namun pengetahuan mengenai takaran dosis, efek samping obat yang mungkin muncul serta cara pengolahan tanaman obat yang akan digunakan belum banyak diketahui oleh masyarakat. Takatan dosis yang salah dan cara pengolahan yang tidak benar akan mengakibatkan tujuan terapi tanaman yang digunakan sebagai obat tidak akan tercapai. Dengan demikian diperlukan pengetahuan cara pemanfaatan tanaman obat.

Obat bahan alam menjadi semakin populer dan penggunaannya meningkat tidak saja di negara sedang berkembang seperti
Indonesia, tetapi juga pada negara maju. Di Indonesia menurut survei nasional tahun 2000, didapatkan $15,6 \%$ masyarakat menggunakan obat tradisional untuk pengobatan sendiri dan jumlah tersebut meningkat menjadi 31,7 \% pada tahun 2001.10 Jenis obat tradisional yang digunakan dapat berupa obat tradisional buatan sendiri, jamu gendong maupun obat tradisional industri pabrik. Penggunaan tumbuhan obat tidak sesederhana seperti yang dipikirkan orang selama ini. Semua harus dipelajari dan memerlukan pengalaman tersendiri. Pemakaian obat tradisional juga harus mempertimbangkan takaran/dosis dan carapengolahan yang tepat agar tujuan terapi tercapai. Namun belum banyak masyarakat mengetahui cara pembuatan obat tradisional yang baik, dimulai dari bagian tanaman obat yang diambil sampai pada tahap pengolahannya. Salah mengenali tumbuhan obat yang dimaksud juga tidak akan menyembuhkan penyakit, apalagi salah menggabungkan beberapa tumbuhan obat yang khasiatnya berlawanan.

Pengabdian ini akan dilaksanakan di RT 02 desa Mendalo Indah kecamatan Jambi Luar Kota. Desa Mendalo Indah termasuk dalam kecamatan Jambi luar Kota Kab. Muaro Jambi merupakan desa hasil pemekaran dari Desa Mendalo Darat. Desa ini mempunyai 12 rukun tetangga. Sedangkan RT 02 pada desa ini mempunyai jumlah 85 kepala keluarga dengan jumlah penduduk lebih kurang 350 orang. Sebagian besar masyarakat Desa Mendalo Indah bermata pencaharian sebagai petani, buruh, pedagang dan pegawai. Desa Mendalo Indah letaknya berdekatan dengan kampus Universitas Jambi. Sebelah utara Desa Mendalo Indah berbatasan dengan desa Mendalo Laut, selatan dengan desa Pematang Gajah, timur dengan desa Mendalo Darat dan sebelah barat berbatasan dengan Desa Simpang Sungai Duren dan Pijoan. Program pengabdian masyarakat ini bertujuan untuk memberikan informasi mengenai cara pengolahan obat tradisonal yang biasa dikonsumsi oleh masyarakat. Setelah pengabdian ini dilaksanakan, diharapkan masyarakat mengetahui dan menerapkan cara pengolahan yang baik obat tradisional yang 
biasa mereka gunakan. Tujuan pengobatan dapat tercapai, efek samping obat menjadi minimal sehingga kualitas kesehatan masyarakat menjadi meningkat.

\section{METODE}

Pelaksanaan program pengabdian kepada masyarakat dalam rangka PPM Pemberdayaan Masyarakat Dalam Pengolahan Tanaman Obat Sebagai Obat Tradisional Di Desa Mendalo Indah Jambi Luar Kota pada masyarakat di RT 02 Desa Mendalo Indah Jambi Luar Kota meliputi 4 tahap, yaitu:

1) pengurusan izin pelaksanaan kegiatan oleh tim pelaksana;

2) penyuluhan tentang pengenalan tanaman obat kepada masyarakat;

3) Memberikan pelatihan keterampilan kepada masyarakat dalam mengolah tanaman obat; dilakukan.

4) evaluasi kegiatan yang telah

\section{HASIL DAN PEMBAHASAN}

Kegiatan pengabdian masyarakat dimulai dari koordinasi dengan ibu-ibu RT 02 desa Mendalo Indah kecamatan Jambi Luar Kota. Desa Mendalo Indah untuk menentukan waktu dan tempat untuk terlaksananya kegiatan penyuluhan "pemberdayaan masyarakat dalam pengolahan tanaman obat sebagai obat tradisional". Tim PPM juga meminta ijin kepada lurah desa setempat untuk pelaksanaan kegiatan tersebut. Pertemuan dihadiri oleh ibuibu RT 02 desa Mendalo Indah kecamatan Jambi Luar Kota. Desa Mendalo Indah. Pengabdian ini dilatarbelakangi oleh penggunaan obat tradisional oleh masyarakat yang tidak terkontrol takaran dan cara pengolahannya. Penyuluhan (lampiran) ini bertujuan memberikan informasi dan pengetahuan jenis obat tradisional untuk mengatasi berbagai penyakit dan memberikan keterampilan kepada masyarakat untuk mengolah obat tradisional sesuai dengan takaran dan cara pembuatan obat tradisional yang baik. Setelah pengabdian ini dilaksanakan, diharapkan masyarakat mengetahui dan menerapkan cara pengolahan yang baik obat tradisional yang biasa mereka gunakan, tujuan pengobatan dapat tercapai, efek samping obat menjadi minimal sehingga kualitas kesehatan masyarakat menjadi meningkat. Pada pengabdian ini juga dilakukan pengecekan tekanan darah gratis.

Hal-hal yang perlu diketahui dalam pengolahan tanaman obat tradisonal meliputi:

1. Saat pemetikan dan pengumpulan
- Daun dikumpulkan sewaktu tanaman berbunga dan sebelum buah menjadi masak

- Bunga dikumpulkan sebelum atau segera setelah mekar

- Buah dipetik dalam keadaan masak

- Biji dikumpulkan dari buah yang masak sempurna

- Akar, rimpang, umbi, umbi lapis dikumpulkan sewaktu pertumbuhannya terhenti

Waktu pemetikan mempengaruhi kadar zat aktif dalam tanaman. Beberapa tanaman memiliki kadar zat aktif yang tinggi pada waktu-waktu tertentu (pagi, siang, atau sore) dan juga dipengaruhi oleh umur dari tanaman tersebut.

2. Pencucian dan pengeringan

- Bahan obat yang sudah dikumpulkan segera dicuci bersih, sebaiknya dengan air yang mengalir. Setelah bersih dapat segera dimanfaatkan bila dibutuhkan dalam keadaan segar atau dikeringkan untuk disimpan dan digunakan bila sewaktu-waktu diperlukan.

- Cara pengeringan: Dipotong terlebih dahulu. Bisa dijemur dengan sinar matahari ataupun diangin-anginkan Pencucian dan pengeringan bertujuan menghilangkan kotoran pada tanaman, dan agar dapat disimpan pada jangka waktu yang lama

3. Cara merebus ramuan obat

- Perebusan dilakukan biasanya sampai airnya mendidih

- Perebusan selesai bila air yang tinggal setengah atau sepertiganya

Perebusan bertujuan menarik zat aktif yang terkandung dalam tanaman. Perebusan juga dilakukan pada jumlah air yang telah ditakar agar dosis pemberian tepat

4. Cara minum Obat

- Biasanya diminum setelah makan untuk obat yang dapat mengiritasi lambung dan yang tidak mengiritasi lambung diminum sebelum makan

- Obat diminum 2-3 kali sehari Beberapa tanaman obat diberikan setelah makan, karena lebih zat aktif bersifat asam. Untuk interval pemberian harus tepat terutama diberikan dalam jangka panjang, ditakutkan nantinya berdampak buruk pada kesehatan

5. Lama pengobatan

- Hasil pengobatan menggunakan tumbuhan obat biasanya efeknya lebih lambat dibandingkan dengan efek kimiawi yang hasil pengobatannya terlihat cepat. Pengobatan dengan tanaman obat biasanya baru memberikan efek dalam jangka waktu yang lama, sehingga butuk kesabaran dari pasien

6. Contoh tanaman obat dan khasiat

Beberapa indikasi dari tanaman obat yang biasa digunakan di masyarakat meliputi: dislipedimia, diabetes, hipertensi, asam urat, demam, sakit gigi, obesitas, anoreksia, diuretic, nefrolitiasis 


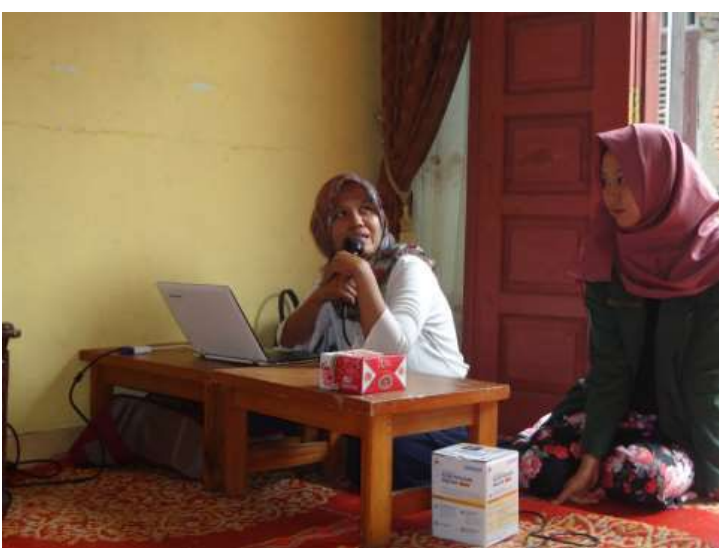

Gambar 1. penyuluhan tentang pengenalan tanaman obat kepada masyarakat

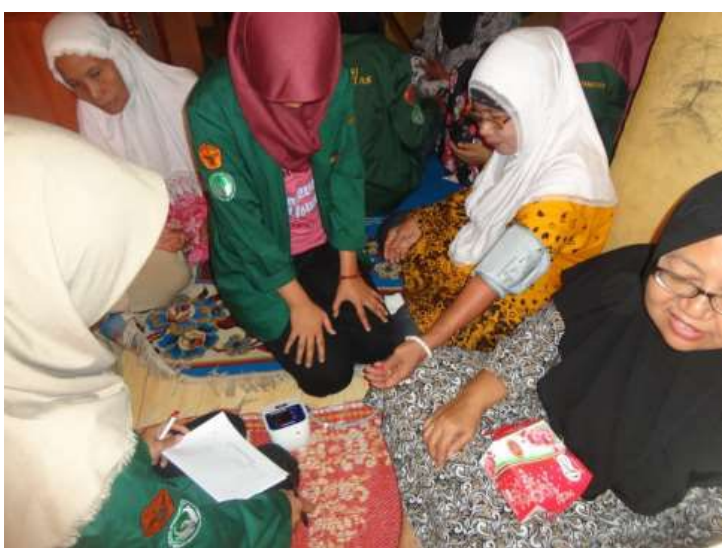

Gambar 2. Pemberian pelatihan keterampilan kepada masyarakat dalam mengolah tanaman obat serta pemeriksaan asam urat gratis

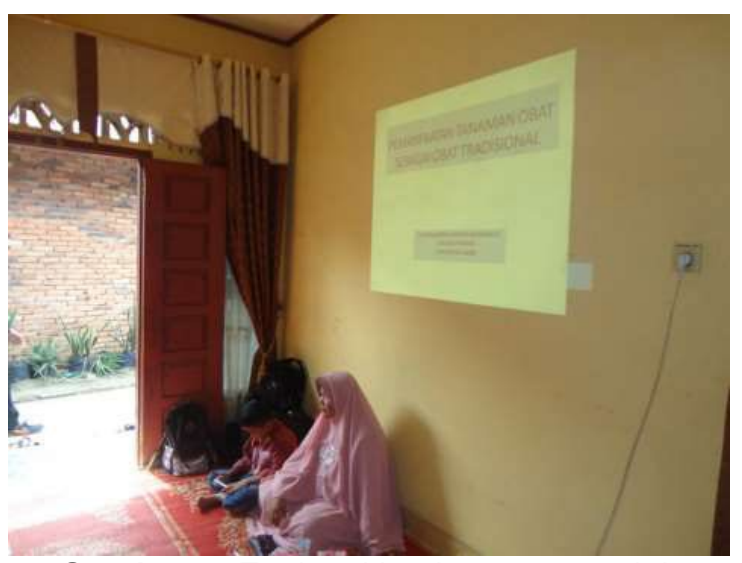

Gambar 3. Evaluasi kegiatan yang telah dilakukan.

\section{SIMPULAN}

Masyarakat telah mengetahui informasi tentang penerapan cara pengolahan obat tradisional yang biasa mereka gunakan secara baik

\section{UCAPAN TERIMAKASIH}

Terima kasih kepada LPPM Universitas Jambi yang telah memberikan dukungan dana, teman-teman dosen dan mahasiswa yang telah membantu sehingga program pengabdian kepada masyarakat ini berjalan dengan lancar hingga selesai.

\section{DAFTAR RUJUKAN}

Departemen Kesehatan, R. (2000). Pedoman Pelaksanaan Uji Klinik Obat. Direktorat Jenderal Pengawasan Obat dan Makanan, Direktorat Pengawasan Obat Tradisional.

Dewoto, H. R. (2007). Pengembangan Obat Tradisional Indonesia Menjadi Fitofarmaka *. Majalah Kedokteran Indonesia.

E, P. (2002). The commercial use of traditional knowledge and medicinal plants in Indonesia. Submitted for multistakeholder dialoque on trade, intellectual property and biological resources in Asia.

Erdelen, WR., Adimihardja, K., Moesdarsono, H. S. (1999). Biodiversity, traditional medicine and the sustainable use of indigenous medicinal plants in Indonesia. Indigenous Knowledge and Development Monitor, 7(3), 3-6.

Pramono, S. (2002). Kontribusi Bahan Obat Alam Dalam Mengatasi Krisis Bahan Obat di Indonesia. Bahan Alam Indonesia. 